\title{
Respiratory Arrest after Postoperative Extubation in a Myasthenic Patient who Received Sugammadex to Reverse Neuromuscular Blockade
}

\author{
Gisoon Park ${ }^{1, *}$, Jae Chan Choi $^{2}$ and Myung Ha Kim ${ }^{3}$ \\ ${ }^{1}$ Resident of Anesthesiology, Department of Anesthesiology and Pain Medicine, Yonsei University Wonju College of Medicine \\ 20 Il San-ro, Wonju-si, Gangwon-do, 26426 (Wonju, South Korea) \\ ${ }^{2}$ Professor of Anesthesiology, Department of Anesthesiology and Pain Medicine, Brain Research Group, Yonsei University Wonju \\ College of Medicine \\ 20 Il San-ro, Wonju-si, Gangwon-do, 26426 (Wonju, South Korea) \\ 3 Librarian, Medical Library, Yonsei University Wonju College of Medicine \\ Gangwon-do (Wonju, South Korea) \\ ${ }^{*}$ Corresponding author's email: sidero1005 [AT] gmail.com
}

\begin{abstract}
Postoperative myasthenic crisis is common after thymectomy; the incidence ranges from 12 to $34 \%$. Several factors are known to predict myasthenic crisis and increased risk necessitating postoperative mechanical ventilation, but incomplete postoperative reversal cannot be prevented perfectly. Sugammadex is a medicine that reverses neuromuscular blockade, and can be used to facilitate the return of spontaneous respiration in myasthenic patients. It was recently reported that myasthenic patients rapidly recovered neuromuscular function when sugammadex was used. An 81-year-old, $49 \mathrm{~kg}$ woman diagnosed with myasthenia gravis one month previously was admitted for intravenous immunoglobulin $G$ treatment and thymectomy. After thymectomy the patient suffered a myasthenic crisis and respiratory arrest, despite administration of sugammadex to reverse the neuromuscular blockade.
\end{abstract}

This case suggests that more careful and strict evaluation and management should be conducted perioperatively in myasthenic patients, and that the recovery time (time to obtain a train-of-four [TOF] value > 0.9) and spontaneous breathing trial results should be obtained to accurately predict the success of spontaneous breathing.

Keywords- Myasthenia gravis, Myasthenic crisis, Thymectomy, Sugammadex

\section{INTRODUCTION}

Myasthenia gravis (MG) is an autoimmune disorder of skeletal muscle neuromuscular junctions (motor end-plates) that is caused by the partial blockade or destruction of nicotinic acetylcholine receptors by IgG antibodies [1]. Thymectomy is performed as an adjunct to pharmacological therapy [2].

MG more severely involves skeletal muscles innervated by cranial nerves [3]. Thus, patients with MG have an increased risk of pulmonary aspiration because of bulbar and oropharyngeal weakness. Additionally, a reduced number of functional acetylcholine receptors results in an increased sensitivity to nondepolarizing neuromuscular blocking drugs (NMBDs) [4]. Anaesthesiologists and physicians should be alerted to the possibility of respiratory failure and pulmonary aspiration in myasthenic patients who have received nondepolarizing NMBDs.

Postoperative myasthenic crisis is common after thymectomy; the incidence ranges from 12 to 34\% [5]. Some factors known to predict myasthenic crisis and increased risk requiring postoperative mechanical ventilation are (1) old age, (2) a disease duration longer than 6 years, (3) previous respiratory problems or coexisting lung disease, (4) high-dose pyridostigmine usage (more than $750 \mathrm{mg} /$ day), (5) a preoperative forced vital capacity (FVC) of less than $2.9 \mathrm{~L}$ and (6) intraoperative blood loss of more than $1 \mathrm{~L}[6,7]$. Although these factors are known, incomplete postoperative reversal cannot be prevented perfectly. Thus, preoperative pulmonary function tests and intraoperative monitoring of neuromuscular transmission should be performed, and sugammadex should be administered to reverse neuromuscular blockade $[8,9]$. 
Sugammadex is a medicine that reverses the neuromuscular blocking effects of NMBDs [9]. This NMBD antagonist acts through a different mechanism than acetylcholinesterase inhibitors. Sugammadex binds directly to the NMBDs and reverses their neuromuscular blocking effects [9].

It was recently reported that myasthenic patients rapidly recovered neuromuscular function when sugammadex was used [2]. We report a case in which myasthenic crisis and respiratory arrest occurred after thymectomy, even though sugammadex was used to reverse a neuromuscular blockade administered during general anaesthesia. This case suggests that successful spontaneous breathing in myasthenic patients cannot be guaranteed, even if sugammadex is administered.

\section{REPORT}

An 81-year-old, 49-kg woman diagnosed with MG one month previously was admitted for intravenous immunoglobulin $\mathrm{G}$ treatment and thymectomy. The patient was a non-smoker, had a history of ptosis and hypertension, and took pyridostigmine (180 mg per day). The following preoperative vital signs were obtained: heart rate (HR, 76 beats per minute), blood pressure (BP, $156 / 99 \mathrm{mmHg})$, respiratory rate (RR, 20 breaths per minute), temperature $\left(37.2^{\circ} \mathrm{C}\right)$ and $\mathrm{SpO}_{2}(98 \%)$. During the preoperative evaluation, mild hypokalaemia $(3.1 \mathrm{mmol} / \mathrm{L})$, an abnormal ECG (sinus rhythm with sinus arrhythmia with a $1^{\text {st }}$-degree AV block, T wave abnormality and prolonged QT), a normal pulmonary function test (FVC 2.42 L, FEV1 1.91 L, FEV1/FVC ratio 79\%) and normal echocardiography were found. The patient was classified as having an American Society of Anesthesiologists physical status of III.

On the morning of the surgery, there was mild respiratory distress. The patient arrived at the operation room for the $1^{\text {st }}$ case surgery with no premedication. General anaesthesia was induced with thiopental $150 \mathrm{mg}$, remifentanil $20 \mathrm{mcg}$ and rocuronium $30 \mathrm{mg}$. The patient was smoothly intubated with a left-sided double-lumen tube, and anaesthesia was maintained with desflurane and remifentanil. An arterial line was inserted at the right radial artery, and a central venous line was inserted at the right internal jugular vein. The operation time was 75 minutes, the anaesthesia time was 140 minutes, and there was no significant event during anaesthesia. Perioperative vital signs were within normal limits (Table 1), intraoperative arterial blood gas analysis (ABGA) was acceptable, and blood loss was minimal $(<300 \mathrm{~mL})$. After 200 mg of sugammadex $(4.1 \mathrm{mg} / \mathrm{Kg})$ was administered, the tidal volume was 250 to $300 \mathrm{~mL}$ and the respiratory rate was 24 breaths per minute. After being extubated in the operation room, the patient was transferred to the surgical intensive care unit (SICU) with an oxygen mask at $5 \mathrm{~L} / \mathrm{min}$. The patient was alert but mildly sleepy and had sputum.

ABGA was performed 15 minutes after ICU arrival, revealing pH 7.308, PCO2 59 mmHg, PO2 $119 \mathrm{mmHg}$ and HCO3- $29 \mathrm{mmol} / \mathrm{L}$. Because of the patient's high PCO2, an oral airway was applied, and spontaneous respiration was encouraged. Thirty minutes after the patient was transferred to the SICU, her respiratory rate increased to 32 breaths per minute, respiratory difficulty and unconsciousness were observed, and bradycardia (40 beats per minute) and a low SpO2 (17\%) were detected. Cardiopulmonary resuscitation was started immediately, ventilation was supported with an Ambu bag, and reintubation was performed. With IV epinephrine $1 \mathrm{mg}$, the return of spontaneous circulation was achieved after 1 minute of chest compression. It was thought that circulation arrest had occurred due to hypoxemia. The day after the event, extubation was attempted, but the spontaneous respiration pattern was shallow and fast, so ventilator care was continued in pressure support mode. Table 2 presents the changes in vital signs from surgery end-time to postoperative day one (POD \#1). The patient was extubated at POD \#13 with generally stable vital signs, except for hypertension (170/83 $\mathrm{mmHg})$. The patient was transferred to the general ward at POD \#14.

Table 1: Changes in vital signs from surgery-start time to surgery-end time.

\begin{tabular}{l|c|c|c|c|c|c}
\hline & $\begin{array}{c}\text { Surgery-start } \\
\text { time }\end{array}$ & $\begin{array}{c}15 \text { min after } \\
\text { surgery-start } \\
\text { time }\end{array}$ & $\begin{array}{c}30 \text { min after } \\
\text { surgery-start } \\
\text { time }\end{array}$ & $\begin{array}{c}45 \text { min after } \\
\text { surgery-start } \\
\text { time }\end{array}$ & $\begin{array}{c}60 \text { min after } \\
\text { surgery-start } \\
\text { time }\end{array}$ & $\begin{array}{c}\text { Surgery-end } \\
\text { time }\end{array}$ \\
\hline $\mathrm{SpO} 2(\%)$ & 100 & 100 & 100 & 100 & 100 & 100 \\
\hline $\begin{array}{l}\mathrm{HR} \\
\text { (beats/min) }\end{array}$ & 65 & 61 & 72 & 65 & 74 & 67 \\
\hline $\begin{array}{l}\mathrm{SBP} / \mathrm{DBP} \\
(\mathrm{mmHg})\end{array}$ & $128 / 61$ & $84 / 47$ & $109 / 62$ & $132 / 60$ & $128 / 70$ & $133 / 66$ \\
\hline $\begin{array}{l}\mathrm{PaO} 2 \\
(\mathrm{mmHg})\end{array}$ & 203 & & & & & 256 \\
\hline $\begin{array}{l}\mathrm{PaCO} 2 \\
(\mathrm{mmHg})\end{array}$ & 34 & & & & & 51 \\
\hline
\end{tabular}


Table 2: Changes in vital signs from surgery end-time to postoperative day one (POD \#1)

\begin{tabular}{|c|c|c|c|c|c|c|c|c|c|}
\hline & $\begin{array}{l}\text { Surgery- } \\
\text { end time }\end{array}$ & $\begin{array}{l}\text { SICU } \\
\text { arrival time }\end{array}$ & $\begin{array}{l}15 \mathrm{~min} \\
\text { after SICU } \\
\text { arrival }\end{array}$ & $\begin{array}{l}\text { Arrest,30 } \\
\text { min after } \\
\text { SICU } \\
\text { arrival }\end{array}$ & $\begin{array}{l}35 \mathrm{~min} \\
\text { after SICU } \\
\text { arrival }\end{array}$ & $\begin{array}{l}40 \mathrm{~min} \\
\text { after SICU } \\
\text { arrival }\end{array}$ & $\begin{array}{l}45 \mathrm{~min} \\
\text { after SICU } \\
\text { arrival }\end{array}$ & $\begin{array}{l}50 \mathrm{~min} \\
\text { after SICU } \\
\text { arrival }\end{array}$ & POD \#1 \\
\hline$\overline{\mathrm{SpO} 2(\%)}$ & 100 & 100 & 90 & 17 & 100 & 100 & 100 & 100 & 100 \\
\hline $\begin{array}{l}\text { HR } \\
\text { (beats/min) }\end{array}$ & 89 & 99 & 101 & 40 & 109 & 110 & 110 & 102 & 76 \\
\hline $\begin{array}{l}\text { SBP/DBP } \\
(\mathrm{mmHg})\end{array}$ & $168 / 85$ & $172 / 102$ & $200 / 84$ & & $186 / 81$ & $170 / 83$ & $171 / 82$ & $192 / 95$ & $157 / 61$ \\
\hline $\begin{array}{l}\mathrm{PaO} 2 \\
(\mathrm{mmHg})\end{array}$ & 256 & & 119 & & & & & 151 & 97 \\
\hline $\begin{array}{l}\mathrm{PaCO} 2 \\
(\mathrm{mmHg})\end{array}$ & 51 & & 59 & & & & & 60 & 51 \\
\hline
\end{tabular}

$\mathrm{SpO} 2$ = blood oxygen saturation. $\mathrm{HR}=$ heart rate. $\mathrm{SBP} / \mathrm{DBP}=$ systolic blood pressure/diastolic blood pressure. $\mathrm{PaO} 2=$ partial pressure of oxygen. $\mathrm{PaCO} 2=$ partial pressure of carbon dioxide. Blank spaces indicate that measurements were not made. During arrest, blood pressure was not measured because it was low, and ABGA was not performed because of the emergency situation.

\section{DISCUSSION}

The cause of postoperative circulation arrest in this case was believed to be hypoxemic respiratory (extracardiac) arrest. Circulation arrest of cardiac origin was excluded because the preoperative echocardiography, perioperative haemodynamics and electrolyte levels were close to normal. Even if a patient recovers early from circulation arrest, postoperative outcomes may be exacerbated. Prolonged mechanical ventilation in response to respiratory arrest increases the risk of pulmonary complications. Postoperative myasthenic crisis occurs in 10 to $24.7 \%$ of myasthenic patients [10, 11]. Although there has been one reported case of recurarization and respiratory failure after administration of sugammadex and rocuronium to a patient with preoperatively undiagnosed myasthenia gravis [12], postoperative circulatory arrest has not been reported in a patient with diagnosed myasthenia gravis. When surgery is scheduled in patients with MG, the following are needed, regardless of the severity of the disease: (1) adequate preoperative evaluation and management of existing pulmonary problems, (2) morning surgery, (3) intraoperative neuromuscular transmission monitoring for adequate doses of NMBDs, (4) administration of sugammadex as a reversal agent, even though the NMBD duration is thought to have ended and (5) most importantly, intensive care unit admission after the operation.

The optimal NMBD dose for myasthenic patients has not been established, and the need for NMBDs to provide an immobile surgical field during operation is controversial. Some clinicians state that volatile agents are sufficient to provide a comfortable surgical environment, while others say that NMBDs are also needed [13]. Because myasthenic patients have increased sensitivity to nondepolarizing NMBDs and prolonged reversal of NMBDs due to a modified response to cholinesterase inhibitors, sugammadex was used as a reversal agent at the end of the operation in this patient [14].

When sugammadex is used, no acetylcholinesterase inhibitors (e.g., atropine or glycopyrrolate) are needed. It was reported that when sugammadex $(4 \mathrm{mg} / \mathrm{kg})$ or a combination of glycopyrrolate and neostigmine was used to reverse an NMBD (rocuronium, $0.6 \mathrm{mg} / \mathrm{kg}$ ), the group that received sugammadex recovered significantly faster than the group that received the combination of glycopyrrolate and neostigmine [15]. In addition, when sugammadex or neostigmine was used to reverse an NMBD (vecuronium) after gen eral anaesthesia, the group that received sugammadex recovered significantly faster than the group that received neostigmine [16].

Sugammadex may be used in patients with myasthenia gravis when faster recovery is needed. Sugammadex was demonstrated to reverse a rocuronium-induced neuromuscular blockade in a patient with myasthenia gravis [17], suggesting that acetylcholinesterase inhibitors can be avoided for the reversal of neuromuscular blockade. In the previous study [2], 10 myasthenic patients were administered $2 \mathrm{mg} / \mathrm{kg}$ of sugammadex after videothoracoscopic-assisted thymectomy. The rocuronium dose was $48 \mathrm{mg}$, and the average operation time was 62 min. The recovery time (time to obtain a TOF value > 0.9) after sugammadex administration was $111 \mathrm{~s}$, and all patients were extubated in the operating room. These findings suggest that myasthenic patients for whom neuromuscular blockade is mandatory during surgery can rapidly recover neuromuscular function if sugammadex is used to reverse the neuromuscular blockade [2]. Therefore, in this case, sugammadex was used to reverse a rocuronium-induced neuromuscular blockade. 
This case suggests that the recovery time and spontaneous breathing trial results should be obtained to accurately predict the success of spontaneous breathing. Train-of-four (TOF) stimulation (4 stimuli at $2 \mathrm{~Hz}, 50$ $\mathrm{mA}$ ) is used to monitor the depth and recovery of the neuromuscular blockade, and the recovery time is the time to obtain a TOF value $>0.9$. When the recovery time increases to 0.9 after sugammadex injection, extubation should be performed, and a weaning plan should be started to assess the success of spontaneous breathing [18]. The three main strategies for performing a spontaneous breathing trial are (1) the T-piece trial, (2) the continuous positive airway pressure (CPAP) trial using CPAP levels and (3) invasive ventilation with a low level of pressure support (5-8 cmH2O). The criteria for a successful spontaneous breathing trial are as follows: (1) respiratory rate $<35$ breaths per minute, (2) good tolerance to spontaneous breathing trials, (3) heart rate < 140 beats per minute or heart rate variability of $20 \%$, (4) arterial oxygen saturation $>90 \%$ or $\mathrm{PaO} 2>60 \mathrm{mmHg}$ on FiO2 $<0.4$, (5) $80<$ systolic blood pressure $<180 \mathrm{mmHg}$, or $<20 \%$ change from baseline and (6) no signs of increased breathing work or distress. If the spontaneous breathing trial is successful, an assessment can be performed for airway removal. In this case, because the patient was elderly and had mild respiratory distress symptoms on the morning of surgery, the recovery time and spontaneous breathing trial results needed to be carefully evaluated.

In conclusion, sugammadex is an effective medicine to reverse the neuromuscular blocking effects of NMBDs in patients with myasthenia gravis. This case suggests that even when sugammadex is administered, incomplete postoperative reversal may occur after a surgery requiring NMBDs to provide an immobile surgical field. This case also suggests that the recovery time (time to obtain a TOF value > 0.9) and spontaneous breathing trial results should be obtained to accurately predict the success of spontaneous breathing, and extubation should be conducted more carefully in myasthenic patients.

\section{REFERENCES}

[1] O'Neill GN, "Acquired disorders of the neuromuscular junction”, International Anesthesiology Clinics, vol 44, pp.107-21, 2006.

[2] Sungur Ulke Z, Yavru A, Camci E, Ozkan B, Toker A, Senturk M, "Rocuronium and sugammadex in patients with myasthenia gravis undergoing thymectomy", Acta Anaesthesiol Scand, vol 57, pp.745-8, 2013.

[3] Nozari A, Bagchi A, Saxena R, Bateman BT, Neuromuscular Disorders and Other Genetic Disorders, Miller's Anesthesia 8edn(Elsevier Saunders), Philadelphia, 2015.

[4] Seigne RD, Scott RP, "Mivacurium chloride and myasthenia gravis", British Journal of Anaesthesia, vol 72, pp.468469, 1994.

[5] Wendell LC, Levine JM, "Myasthenic crisis”, Neurohospitalist, vol 1, pp.16-22, 2011.

[6] Eisenkraft JB, Papatestas AE, Kahn CH, Mora CT, Fagerstrom R, Genkins G, "Predicting the need for postoperative mechanical ventilation in myasthenia gravis", Anesthesiology, vol 65, pp.79-82, 1986.

[7] Watanabe A, Watanabe T, Obama T, et al, "Prognostic factors for myasthenic crisis after transsternal thymectomy in patients with myasthenia gravis", Journal of Thoracic and Cardiovascular Surgery, vol 127, pp.868-76, 2004.

[8] Blichfeldt-Lauridsen L, Hansen BD, “Anesthesia and myasthenia gravis”, Acta Anaesthesiol Scand, vol 56, pp.1722, 2012.

[9] Kim RK, Kim SY, "Rapid Return of Spontaneous Respiration after General Anesthesia with Sugammadex in a Patient with Myasthenia Gravis", Journal of Lifestyle Medicine, vol 6, pp.43-6, 2016.

[10] Xue L, Wang L, Dong J, et al, "Risk factors of myasthenic crisis after thymectomy for thymoma patients with myasthenia gravis", European Journal of Cardio-Thoracic Surgery, vol 52, pp.692-7, 2017.

[11] Yu S, Lin J, Fu X, et al, "Risk factors of myasthenic crisis after thymectomy in 178 generalized myasthenia gravis patients in a five-year follow-up study", International Journal of Neuroscience, vol 124, pp.792-8, 2014.

[12] Ozel F, Altunkan AA, Azizoglu M, "Postoperative respiratory failure in a patient with undiagnosed myastenia gravis", Turkish Journal of Anaesthesiology and Reanimation, vol 44, pp.108-10, 2016.

[13] Kiran U, Choudhury M, Saxena N, Kapoor P, "Sevoflurane as a sole anaesthetic for thymectomy in myasthenia gravis", Acta Anaesthesiol Scand, vol 44, pp.351-3, 2000.

[14] Kim JM, Mangold J, "Sensitivity to both vecuronium and neostigmine in a sero-negative myasthenic patient", Br J Anaesth,vol 63, pp.497-500, 1989. 
[15] Jones RK, Caldwell JE, Brull SJ, Soto RG, "Reversal of profound rocuronium-induced blockade with sugammadex: a randomized comparison with neostigmine", Anesthesiology,vol 109, pp.816-24, 2008.

[16] Lemmens HJ, El-Orbany MI, Berry J, Morte JB, Jr., Martin G, "Reversal of profound vecuronium-induced neuromuscular block under sevoflurane anesthesia: sugammadex versus neostigmine", BMC Anesthesiol, vol 10, pp.15, 2010.

[17] Komasawa N, Noma H, Sugi T, Sukenaga N, Kakiuchi H, "Effective reversal of muscle relaxation by rocuronium using sugammadex in a patient with myasthenia gravis undergoing laparoscopic cholecystectomy", Masui, vol 60, pp.476-9, 2011.

[18]Zein H, Baratloo A, Negida A, Safari S, "Ventilator Weaning and Spontaneous Breathing Trials; an Educational Review", Emerg (Tehran), vol 4, pp.65-71, 2016. 